\title{
Dumansız Bir Çevre Mücadelesi: Dünden Bugüne
}

\section{The Struggle for a Smoke-Free Environment: From Past to Today}

\author{
Hasan Çetin Ekerbiçer', Ufuk Berberoğlu², Mustafa Baran Inci \\ 'Sakarya Üniversitesi Tıp Fakültesi Halk Sağlığı Anabilim Dalı, Sakarya \\ 2 Uşak Üniversitesi Tıp Fakültesi Halk Sağlığı Anabilim Dalı, Uşak
}

Yazıșma Adresi / Correspondence:

Mustafa Baran İnci

Sakarya Üniversitesi Tıp Fakültesi Halk Sağlığı Anabilim Dalı, Korucuk, Adapazarı, Sakarya
T: +9026429531
E-mail: mbinci@sakarya.edu.tr

Geliş Tarihi / Received : 31.08.2018 Kabul Tarihi / Accepted : 03.09.2018

\begin{abstract}
Öz
Tütün kullanımı, tüm dünyada en yaygın önlenebilir mor-talite nedeni olarak kabul edilmektedir. Halk Sağlığı açııından önemi, bağı̆llık yapııı olması, kullanan kișilerin hastalanması ve erken ölmesi, dumanına maruz kalanların da benzer risklerle karșı karşıya kalması nedeniyledir. On yetișkin ölümünden birinin sorum-lusudur ve dünyada en sık sekiz ölüm nedeninden altı tanesi için risk faktörüdür. Osmanlı Devleti döneminde tütün kullanımı ile mücadele zaman zaman etkin olsa da tütün kullanımı o dönemlerden günümüze kadar devam etmiştir. Son yıllarda, 4207 sayılı “Tütün Ürünlerinin Zararlarının Önlenmesi ve Kontrolü Hakkında Kanun” ile önemli bir adım atılmıştır. Dünya Sağık Örgütü "Tütün Kontrol Çerceve Sözlesmesi (TKCSS)", 2004 yllında ülkemizde de kabul edilmistir. 5727 sayllı "Tütün Mamullerinin Zararlarının Önlenmesine Dair Kanunda Değişiklik Yapııması Hakkında Kanun ile 19 Temmuz 2009 tarihinde tüm yasal düzenlemeler yürürlüğe girmiştir. 2018-2023 Tütün Kontrolü Strateji Belgesi ve Eylem Planı ile mücadelede yeni bir dönem başlayacaktır. Ülkemizin tütün mücadelesinde gösterdiği kararlı tutumun, toplumun tüm katmanlarınca desteklenmesi, gelecek nesillerin sağı̆̆ı ve refahı için vazgeçilmez bir gerekliliktir. ( Sakarya Tip Dergisi 2018, 8(3):470-474 )

Anahtar Tütün Kullanımı; Tütün Kontrolü; DSÖ

Tobacco use is considered the most common preventable mortality reason in the world. In terms of public health, it has an addictive nature, the people who use it are generally get sick and die early and those exposed to second-hand smoke also face similar risks. It is the responsible of one of ten deaths in adults and is the risk factor for six of the eight most common causes of death in the world. Although the struggle against tobacco use during the Ottoman period was effective from time to time, the use of tobacco continued for many years. In recent years, an important step has been taken with Law No. 4207 on “Prevention and Control of Hazards of Tobacco Products". The World Health Organization " Framework Convention on Tobacco Control (FCTC)" was also adopted in 2004 in our country. On July 19, 2009, all legal regulations entered into force with the "Law on the Amendment of the Law on the Prevention of Hazards of Tobacco Products" numbered 5727. A new era will begin in the struggle with the "2018-2023 Tobacco Control Strategy Document and Action Plan". In all layers of society of our country, supporting the determined attitude on tobacco struggle is an essential requirement for the health and well-being of future generations. ( Sakarya Med J, 2018, 8(3):470-474 ). 
Sakarya Tip Dergisi 2018;8(3):470-474

EKERBiçER ve Ark. Dumansız Bir Çevre Mücadelesi: Dünden Bugüne

\section{Giriş}

Tütün ve tütün ürünlerinin kullanımı, Dünya Sağlık Örgütü (DSÖ) tarafından en tehlikeli ve önlenebilir halk sağlığı tehditlerinden biri olarak gösterilmektedir. Kullananların yanı sıra, tütün dumanına maruz kalanlar da aynı şekilde etkilenmektedir. Dünyada yılda 7 milyondan fazla, ülkemizde de 100.000'den fazla kişi tütün ürünü kullanımına bağı hastalıklar nedeniyle hayatını kaybetmektedir. ${ }^{1}$ Öte yandan, günümüzde tütün kullanımı, tüm dünyada en yaygın önlenebilir mortalite nedeni olarak kabul edilmektedir. ${ }^{2}$ Halk Sağığı açısından bakıldığında ise önemi, bağımlılık yapııı olması, kullanan kişilerin hastalanması ve erken ölmesi, dumanına maruz kalanların da benzer risklerle karşı karşıya kalması nedeniyledir. ${ }^{3}$

Tütüne bağı ölümler, Tüberküloz, HIV/AIDS ve Sıtmaya bağlı ölümlerin toplamından daha fazladır. 2030 yııında bu sayının 8 milyonu bulması, gerekli önlemler alınmadığı takdirde bu yüzyıl boyunca tütün kullanımının 1 milyar kişinin ölümüne neden olması beklenmektedir. ${ }^{4-6}$ On yetişkin ölümünden birinin sorumlusudur ve dünyadaki en sık sekiz ölüm nedeninden altı tanesi için risk faktörüdür. Önlenebilir ölümlerin en önemli nedenlerindendir. ${ }^{7}$

Dünyada toplam 1,3 milyar kişi sigara içmektedir. Kadınlarda sigara içme oranı erkeklere oranla daha az olmakla birlikte son yıllarda bu oranın da artmış olduğu bilinmektedir. Hindistan, Endonezya ve Çin bu sayının çoğunluğunu oluşturmakta ve toplam sigara içenlerin \% 75 gibi büyük bölümü Türkiye'nin de aralarında olduğu 10 ülkede yaşamaktadır. ${ }^{8}$ Dünya genelinde tütün ürünü kullananların yaklaşık \% 80'i düşük ve orta gelirli ülkelerde yaşamaktadır. Halk sağlığını bu denli tehdit eden tütün kullanımı ile mücadele özellikle bu ülkelerde çok büyük önem taşımaktadır. ${ }^{9}$

Öte yandan tütün kullanımı, bağımlılık yapan başka maddelere de geçişin ilk adımıdır. Bundan dolayı, tütün kullanımının önlenmesi aynı zamanda diğer bağımlılık yapıcı maddelere geçişi de engellemiş olacaktır. Tüm bu nedenler, tütün mücadelesinin önemini daha da artırmaktadır.

\section{Tütün Kontrolünün Ülkemizdeki Tarihçesi}

Tütün ürünleri kullanımı ile mücadelenin tarihsel geçmişine bakıldığında; Osmanlı Devleti döneminde tütün kullanımı ile mücadele zaman zaman şiddetlenmekle birlikte tütün kullanılmaya devam edilmiştir. Örneğin, I. Ahmet döneminde şeyhülislam tütün kullanımının haram olduğu yönünde fetva yayınlamış ve sigara kullanımının yasaklanmasını istemiştir. ${ }^{10}$ Uygulama başarılı olamamış, hatta IV. Murat Döneminde uygulanan aşıı tedbirler bile sigara kullanımıyla mücadelede etkin sonuç alınmasını sağlayamamıştır.

Sonraki yıllarda, tütün ürünleri kullanımı ile mücadele, uzunca bir dönem boyunca Yeşilay derneğinin çabaları ile sınırı kalmıştır. 1920 yılında "Hilal-i Ahdar" adıyla kurulan dernek, 1934 yılında kamuya yararlı dernek statüsü almıştı. Öncelikle alkol bağımlılığı ile mücadele çalışmaları yürüten, sonraları sigara, uyuşturucu ve kumar gibi diğer bağımlılık türleri ile mücadele eden dernek günümüzde de varlığını sürdürmektedir. ${ }^{11}$

26 Kasım 1996 tarih ve 22829 sayllı resmi gazetede yayınlanarak yürürlüğe giren 4207 sayılı “Tütün Ürünlerinin Zararlarının Önlenmesi ve Kontrolü Hakkında Kanun” ile bu konuda ilk adım atılmışır. ${ }^{12}$ Bu yasa, toplu taşıma araçlarında sigara içmeyi yasaklaması, paketlerde uyarıların yer alması, 18 yaş altındakilere sigara satışının yasaklanması, sigara kullanımını özendirici reklam ve 
teşvik kampanyalarını engellemesi ve televizyonlarda sigaranın zararları ile ilgili yayın zorunluluğu getirmesi gibi konularda katkı sağlamıştır. ${ }^{13}$

\section{Dünya Sağlık Örgütü Çerçeve Sözleşmesi}

Ülkemizde 4207 sayılı “Tütün Ürünlerinin Zararlarının Önlenmesi ve Kontrolü Hakkında Kanun” çıktıktan sonraki yılları takiben, 2003 yılında Cenevre'de, DSÖ 56. Dünya Sağlık Asamblesi'nde kabul edilen, tütün kullanımının önlenmesi yanında endüstrisinin yayılma ve pazar oluşturma stratejilerine karşı geliştirilen ve bu alandaki ilk uluslararası anlaşma olma özelliğini taşıyan “Dünya Sağlık Örgütü Tütün Kontrol Çerçeve Sözleşmesi (TKÇS)" dünya kamuoyunun gündemine gelmiştir.

Söz konusu sözleşme çok geçmeden, 30 Kasım 2004 tarihli ve 25656 sayılı Resmi Gazete'de yayımlanarak ülkemizde de yürürlüğe girmiştir. Ülkemiz sözleşmeyi imzalayan 43. ülke olmuştur. Günümüzde, dünya nüfusunun \% 90'ından fazlasının yaşadığı 181 ülke, sözleşmeyi imzalamış ve taraf olmuştur. Bu sözleşmenin kabul edilmesi, ülkemizde etkili bir tütün mücadelesinin başlangıcını teşkil etmiştir.

DSÖ Çerçeve Sözleşmesinin hedefi, tütünle ilişkili hastalıklardan korunma ve sağlığı geliştirmektir. Örgüt, ülkelere bu yönde yardım etmek için, M-POWER paketini hazırlamıştır. Bu pakette tütün kontrolünde en etkili altı politika ele alınmaktadır. Bunlar; Monitor-tütün kullanımını ve koruma politikalarını izlemek, Protect-toplumu tütün dumanından korumak, Offer-tütün kullanımını bırakmaya yardım etmek, Warn-tütünün zararları hakkında uyarılarda bulunmak, Enforce-tütün reklamlarını yasaklamak ve Raise-tütün ürünlerinden alınan vergiyi artırmaktır. Tütün mücadelesinde etkili izlemenin önemine dikkat çekilmiş ve M-POWER paketi politikalarında yer alan çalışmaların sonuçları ise örgütün 2015 yılı raporunda yer almıştır. ${ }^{14}$

5727 sayılı Tütün Mamullerinin Zararlarının Önlenmesine Dair Kanunda Değişiklik Yapılması Hakkında Kanun'un 19 Mayıs 2008 tarihinde kısmen, 19 Temmuz 2009 tarihinde ise tümüyle yürürlüğe girmesi (özel hukuk kişilerine ait olan lokanta, kahvehane, kafeterya, birahane gibi eğlence hizmeti verilen işletmelerde tütün ürünleri tüketilmemesi hükmü de dahil) ile günümüzde halen süren tütün mücadelesi çalışmaları başlamıştır. Bu kanunla birlikte ikamete mahsus konutlar hariç tüm kapalı alanlarda tütün ürünü kullanma yasağı getirilmiştir. ${ }^{12}$

Ülkemizde 19 Temmuz 2009 düzenlemeleri, dünyada sigara ile mücadelede yeni bir anlayışı temsil eden Tütün Kontrolü ve Çerçeve Sözleşmesi çerçevesinde uygulamaya konulmuştur. Bu yasa ile, 4207 sayılı kanunun çıkışından yaklaşık 13 yıl sonra, tüm kapalı alanlarda tütün kullanımı yasaklanmıştır. Uygulamanın başlamasını takiben, tütün kullanım sıklığı azalmaya başlamıştır. Türkiye sigara ile mücadelede en katı önlemleri içeren bu yeni anlayışı hayata geçiren dünyada altıncı, Avrupa'da üçüncü ülke olmuştur. ${ }^{13}$ Etkili mücadelenin başlamasının yansıması olarak, 2008 ile 2012 yılları arasında Türkiye'de tütün kullanım sıklığı \% 31,2'den \% 27,1'e gerilemiştir. Sonrasında yeniden yükselişe geçmiş ve 2016 'da \% 31.6'ya yükselmiştir. ${ }^{15}$

2015 yılında Ulusal Tütün Kontrol Programı Eylem Planında (2015 - 2018) yer alan bazı hususların uygulanmasına yönelik çalışmaların başlatılmasına dair Sağlık Bakanlığı'nın genelgesi ile mücadele uygulamaları son şeklini almıştır.
Sakarya Tip Dergisi 2018;8(3):470-474

EKERBiÇER ve Ark. Dumansız Bir Cevre Mücadelesi: Dünden Bugüne 
Sakarya Tip Dergisi

2018;8(3):470-474

EKERBiCER ve Ark.

Dumansız Bir Çevre Mücadelesi: Dünden Bugüne

22 yıl önce 4207 saylı yasa ile başlayan süreçte gelinen noktaya bakacak olursak; o dönem ile karşılaştırıldığında oldukça iyi bir duruma gelinmiştir. Hatta Dünya Sağlık Örgütü raporlarında, sigara ile mücadelede ülkemiz, diğer ülkeler için örnek olarak gösterilmiştir. ${ }^{16}$

Bir süre önce açıklanan 2018-2023 Tütün Kontrolü Strateji Belgesi ve Eylem Planı ile mücadelede yeni bir döneme girilmiştir. Bu dönemde, dumansız hava sahasının genişletilmesi, tütün ürünlerinin satışının 21 yaşının altındakilere yapılmaması ve satış-sunum yerlerinin örgün eğitim kurumları ve öğrenci yurtlarına en az 500 metre uzaklıkta olması, tütün ürünlerindeki vergilerin artırılması, düz paket uygulaması, sigara içilmesi yasak kapalı alanlara yönelik denetimlerin artırılması, sigara kullanmayan personele pozitif ayrımcılık uygulamaları ve sigarasız kurumların teşvik edilmesi gibi birçok düzenleme yapılması planlanmaktadır. ${ }^{17}$

\section{Sonuç}

Tütün mücadelesine yeni bir ivme kazandırması beklenen yeni eylem planının, toplumun tüm paydaşları tarafından desteklenmesi için gerekli bilgilendirme eğitimlerinin yapılması başarı şansını artıracaktır. Dünya Sağıık Örgütü önderliğinde tütün kullanımına karşı yürütülen küresel mücadelede, ülkemiz çok önemli toplumsal dönüşümleri başarmıştır. Bunun artarak sürmesi büyük önem taşımaktadır. İstenen sonuçlara hızla ulaşılamaması, bağımlıık mekanizmalarının karmaşık yapısından kaynaklanmaktadır. Ülkemizin 1996'da başlayan, 2009 yılında ivme kazanan tütün mücadelesinde gösterdiği kararlı tutumun, toplumun tüm katmanlarınca desteklenmesi, gelecek nesillerin sağlığı ve refahı için vazgeçilmez bir gerekliliktir. 
1. World Health Organization Tobacco Fact Sheets http://www.who.int/ en/news-room/fact-sheets/detail/tobacco Erișim: 24.05.2018.

2. World Health Organization Tobacco Free Initiative. Bu-ilding blocks for tobacco control: a handbook. WHO 2015 pp 4-13. http://www.who. int/tobacco/resources/publications/tobaccocontrol_handbook/en/ Erişim Tarihi 24.05.2018.

3. Aslan D. Dünya'da ve Türkiye' de tütün kullanımı: riskler, tehditler, önleyici yaklaşımlar. J Pulm Med-Special Topics 2012;5:1-5.

4. Ergüder T. Dünyada Tütün Kontrolü ve Dünya Sağlık Örgütü Önerileri MPOWER. Aytemur A, Akçay A, Elbek O (Eds). Tütün ve Tütün Kontrolü. Toraks Kitapları, Türk Toraks Derneği, 2010; 81-93

5. Aslan D, Şengelen M. Dünya Sağlık Örgütü 31 Mayıs “Tütünsüz Bir Dünya Günü” Konularının Tütün Kontrolü Bakış Açısılla Değerlendirilmesi. STED 2014; 23 (özel sayı), 1-3.

6. Kılınç O, Günay T. Türkiye Tütün Kontrolünde Hangi Noktada: Engeller ve Çözüm Önerileri. STED 2014; 23 (özel sayı), 4-7.

7. Ergüder T. Tütün kontrol kavramı ve Dünya Sağık Örgütü yaklaşımı. Pulm Med-Special Topics 2012;5:11-15.

8. WHO Report On The Global Tobacco Epidemic (MPOWER), 2008, WHO, Geneva

9. World Health Organization. Why tobacco is a public health priority. Tobacco Free Initiative (TFI)

10.Barış Y. i.., "Tütün Kullanımının Tarihçesi",www.toraks.org.tr/userfiles/ file/tutun_kullanımının tarihcesi baris. pdf, Erişim : 28.06.2018
11. Yeşilay Tarihçesi, https://www.yesilay.org.tr/tr/kurumsal/tarihce Erişim : 20.07.2018

12. Tütün Mamullerinin Zararlarının Önlenmesine Dair Kanun, No 4207, 26 Kasım 1996 tarihli ve 22829 sayılı Resmi Gazete (Değişiklik, 03.01.2008 tarih ve 5727 Sayilı Kanun, 19 Ocak 2008 tarihli ve 26761 sayilı Resmi Gazete.

13. Joossens L \& Raw M. Tobacco Control Scale, A Report of the Asociation of European Cancer League, Brussels, Belgium 2010. Fifth European Conference on Tobacco or Health, Amsterdam, Netherlands, 28-30 March 2011.

14. World Health Organization. WHO report on the global tobacco epidemic, 2015: raising taxes on tobacco, 2015. www.who.int/tobacco/ global_report/2015/report/en/Erişim Tarihi 20.07.2018

15. Türkiye Halk Sağlğı Kurumu Küresel Yetişkin Tütün Araştırması Türkiye 2012. Sağlık Bakanlığı Yayın No: 948 ISBN: 978-975-590-502-0, Ankara; 2012 http://www.halksagligiens.hacettepe.edu.tr/KYTA_TR.pdf, Erişim Tarihi: 31.07.2018.

16. World Health Organization. WHO report on the global tobacco epidemic 2013. http://www.who.int/tobacco/global_report/2013/en/. Erişim:19.07.2018.

17. Tütün Kontrolü Strateji Belgesi ve Eylem Planı 2018-2023 https:// hsgm.saglik.gov.tr/depo/birimler/tutun-mucadele-bagimlilik-db/ haberler/tutun_eylem_plani/Tutun_Kontrolu_Strateji_Belgesi_ve_Eylem_Plani.pdf Erişim: 28.07. 2018
Sakarya TIp Dergisi

$2018 ; 8(3): 470-474$

EKERBiçER ve Ark.

Dumansız Bir Çevre Mücadelesi: Dünden Bugüne 